\title{
"Anhangabahú": a redescoberta do centro de São Paulo
}

\author{
Lucio Gomes Machado
}

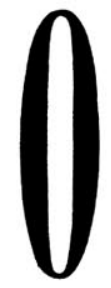

impacto causado na vida dos paulistanos pelas obras desenvolvidas no vale do Anhangabaú, e que estão por ser agora inauguradas, retomou um debate esquecido entre nós: a estética da cidade, a cidade que queremos e a cidade que os governantes têm projetado e construído. Tais obras são, em parte, o resultado de concurso público organizado há cerca de dez anos pelo IAB - Instituto dos Arquitetos do Brasil e pela EMURB, empresa municipal encarregada de promover programas de urbanização na cidade de São Paulo, mas não se incorporam a um programa global de política urbana continuada do município.

O projeto para o novo vale do Anhangabaú, escolhido na ocasião por júri altamente qualificado, foi objeto de certa polêmica no meio profissional e, é importante reconhecer, não nasceu do debate público sobre os destinos do centro da cidade. Foi mais fruto do trabalho do corpo técnico da prefeitura do munić́pio e da equipe de arquitetos e paisagistas responsável pela sua autoria e posterior desenvolvimento(1) que uma demanda da população.

De fato, a grande maioria dos habitantes de São Paulo não conhece a sua cidade nem tem o hábito de refletir sobre seus destinos. A intensa migração que a transformou na maior cidade nordestina, na maior cidade japonesa fora do Japão, numa enorme cidade italiana, portuguesa ou coreana, é um dos indicadores a que se atribui a falta de identificação entre ela e seus habitantes. Por outro lado, a alteração do quadro econômico de São Paulo, no decorrer do último século, foi acompanhada de sucessivas reconstruções da cidade ou, como sintetizou Benedito Lima de Toledo em São Paulo três cidades em um século, a cidade de taipa, a de tijolos e a de concreto foram construídas sobre o mesmo sítio, com tal descompromisso com as gerações passadas, que dificilmente é hoje possível, ao cidadão comum, reconhecer as fases anteriores.

O desconhecimento da história da cidade é outro fator importante que merece destaque. Como se sabe, se os arquivos sobre a história política de São Paulo são precários, a história da urbanização da cidade está ainda quase que por ser feita, sobretudo no que se relaciona com a reconstituição do espaço e das construções. De imediato, lembramonos da abundância de imagens sobre as intervenções realizadas no Rio de Janeiro, recolhidas, por exemplo, por Gilberto Ferrez ${ }^{(2)}$. Quanto a São Paulo, até mesmo as preciosas coleções de fotografias de Augusto Militão correm o risco de deterioração por falta de meios adequados para a sua conservação.

Para a construção da história da Arquitetura e do Urbanismo da cidade de São Paulo, relativa ao último século, foram fundamentais os trabalhos pioneiros e as diretrizes de pesquisa lançadas por membros do Departamento de História da Arquitetura e Estética do Projeto da Faculdade de Arquitetura e Urbanismo da USP, destacando-se entre eles Nestor Goulart Reis Filho, Carlos A. C. Lemos e Benedito Lima de Toledo(3). Paralelamente a pesquisadores europeus, como Leonardo Benevolo(4), sistematizaram em seus cursos a importância da interdependência entre história, sociedade e projeto, em espe-
LUCIO GOMES MACHADO \& arquiteto e professor da Faculdade de Arquitetura e Urbanismo da USP.

Anhangabaho, Benedito Lima de Toledo. Săo Paulo, FIESPICIESP, 212 pp.
1 A equipe vencedora do concurso era liderada pelos arquitetos Jorge $\mathrm{Wi}$ Iheim e Rosa Grena Klias.

2 Entre outros trabalhos de grande interesse poderfamos colocar como exemplos: $O$ Rio antigo do fotografo Marc Ferrez. Paisagens e tipos humanos do Rio de Janeiro 1865-1918. Gilberto Ferrez, São Paulo, Ex-Libris, 1985 e $O$ álbum da Avenida Central, Rio de Janeiro, 1903-1906. Marc Ferrez, introduçăo de Gilber.

3 Entre os trabalhos desses professores, nesse campo, podemos destaca as seguintes publicaçōes: Quadro da arquitetura brasileira, Nestor Goulart Reis Filho, Săo Paulo, Perspectiva, 1970. Alvenaria burguesa Partiva, . Caul, 1985 Sáo Paulo: três cidades em um sô culo, Benedito Lima de Toledo, Săo Paulo, Duas Cidades, 1981. Nesta última obra o autor desenvolve a re constituição da história de diversos outros logradouros de São Paulo, com mótodo anślogo ao utilizado em com mólodo análogo ao utilizado em sucinta.

4 Storia dell'architetura moderna, Leonardo Benevolo, Laterza, Bari, 1966.

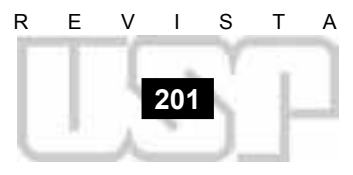


No início do século, o primeiro viaduto já é utilizado pelos bondes elétricos. À esquerda, 0 teatro Săo José ocupa o terreno onde será posteriormente construida a sede da Light; a direita, o teatro Municipal em final de construção. Na outra página, o edifício Martinelli visto da avenida São João, nas proximidades do parque do Anhangabaú cial quando este se relaciona com o desenho urbano.

Intervenções em áreas urbanas, na escala da realizada no centro de São Paulo, deveriam ser antecedidas por extensas pesquisas sobre sua história. Se isso não foi possível por ocasião da organização do concurso que originou o projeto em execução no vale do Anhangabaú ou, pelo menos, não com a profundidade desejável, um dos méritos do projeto vencedor ê a forma com que proporcionou a restituição do seu espaço aos pedestres, ao convívio dos cidadãos, isto é, a recuperação do vale como parque da cidade, o que, aliás, era um dos objetivos do concurso.

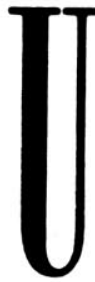

ma análise mais minuciosa da importância que teve o espaço do vale para a caracterização, no século passado, do centro da cidade de São Paulo, pode agora ser realizada por um número maior de pessoas em razão da publicação da obra de Benedito Lima de Toledo, Anhangabahú, patrocinado pela Federação das Indústrias de São Paulo. O livro, com cuidadosa elaboração gráfica de Diana Mindlin, reproduz uma importantíssima coleção de imagens daquela região, desde um desenho de Tomas Ender (1827) a plantas e fotografias pertencentes a arquivos oficiais e particulares (214 ilustrações sobre um trecho com menos de um quilômetro!). Algumas das imagens são bem conhecidas, outras raríssimas, e o conjunto certamente deverá surpreender até mesmo os estudiosos da área, além de proporcionar, a qualquer interessado pelo tema, uma surpreendente viagem a um tempo em que São Paulo se propunha ser uma cidade europeria.

À parte o trabalho de análise da história da urbanização, merece um destaque especial a sistemática busca de fontes de documentos para estudo. A carência de imagens, matéria-prima fundamental para a reconstituição do espaço, é constante nesse tipo de trabalho e só recentemente é que se iniciou, no âmbito universitário, trabalho sistemático de coleta de iconografia relacionada com a construção das nossas cidades. Nesse caso, foi possível tamberm contar com a colaboração de colecionadores particulares de fotografias antigas, e sobretudo de colecionadores de cartões-postais, os quais têm se mostrado fonte fundamental para a reconstituição desse aspecto da história. Tão importante era o vale para a caracterização da imagem da cidade que pode o autor encontrar imagens que resgatam, passo a passo, a construção dos vários setores do parque, dos seus equipamentos e dos edifícios que limitavam e configuravam seu espaço.

Alguns dos edifícios que formavam a paisagem do vale são marcos da arquitetura paulistana, mas não mantêm o destaque original em razão da multiplicidade caótica das construções à sua volta. Como exemplo, podemos citar o primeiro "arranha-céu" paulistano, o edifício Sampaio Moreira (1924), projeto do arquiteto Christiano Stockler das Neves, construído pelo Escritório Técnico Samuel das Neves, o mesmo que já teria construído outras obras de concreto armado na rua Líbero Badaró, introduzindo a técnica que caracterizaria a verticalização de São Paulo, ou ainda o edif́́cio Martinelli, rapi-
5 Desenhos e fotografias da quase totalidade das obras de Ramos de Azevedo, Samuel das Neves, Christiano Stockler das Neves e Elisiário da CuTha Bahiana estăo conservado rados no acervo de projetos da Biblioteca da Faculdade de Arquitetura e Urbanismo da USP.

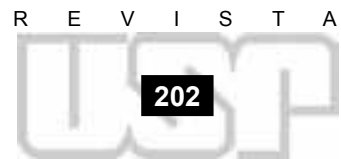

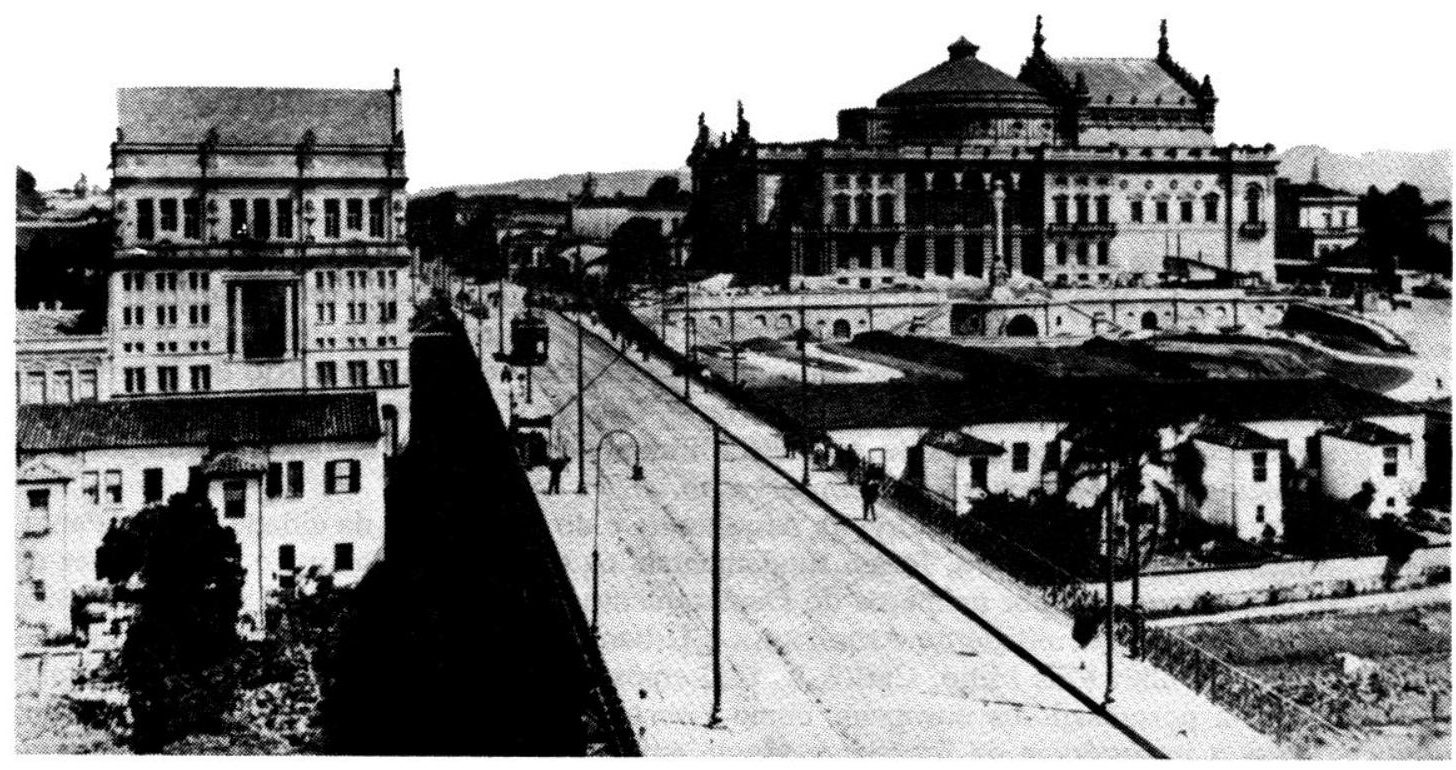

Dezembro

Janeiro

Fevereiro

1990-1991 
damente transformado em símbolo da modernidade de São Paulo, a despeito do seu estilo indefinido, que é também retratado em múltiplas vistas nos cartões-postais durante a sua construçāo. $\mathrm{O}$ Teatro Municipal, construído pelo Escritório Ramos de Azevedo com o concurso dos arquitetos Domiziano Rossi e Claudio Rossi, por sua posição e integração no parque, e tendo em vista o vulto e a qualidade de sua arquitetu$\mathrm{ra}$, \& a personagem central dos cartões-postais e das fotografias panorâmicas. Talvez tenha sido o primeiro dos edifícios situados no vale que mereceram atenção especial quanto ao agenciamento na paisagem e na complementação da obra com a sua extensão ao entorno, com o detalhamento do traçado viário, caminhos para pedestres e implantação de esculturas com estilo idêntico às do ediff́cio principal e que provavelmente induziu à continuidade do trabalho de qualidade ali observado.

Christiano Stockler das Neves era, na época, arquiteto de grande influência na formação dos arquitetos - foi o organizador da escola de arquitetura do Mackenzie - e era importante divulgador da arquitetura neoclássica. Outro arquiteto muito influente na formação das novas gerações de arquitetos, mas favorável à adoção das tendências modernistas, Elisiário Bahiana, aparece como autor das últimas intervençôes edificadas no vale retratadas no livro: o novo viaduto do Chá e o edifício do Mappin. O vale, centro de interesse da cidade, era, assim, a vitrine para o ensaio das últimas tendências da arquitetura em São Paulo ${ }^{(5)}$.

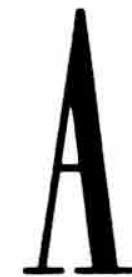

specto particularmente interessante no livro é a sua estrutura, levando o leitor a gradativamente perceber que o vale foi sendo construído progressivamente, até o IV Centenário da cidade, com o trabalho de gerações 1 Le administradores públicos, técni$\cos$, artistas e cidadãos, acumulando cuidadosas contribuições. Aliando-se intervenções no traçado viário à minuciosa compatibilização, caso a caso, dos edif́́cios existentes ou a serem construídos, com a vizinhança, foi possível obter um conjunto extremamente rico em soluções e em elementos originais. Com este trabalho de contribuições sucessivas, Benedito Lima de Toledo destaca ter resultado a construção do parque do Anhangabaú na criação ou na remodelação de "sete praças" a ele associadas, as quais são parte da configuraçāo do seu espaço: Patriarca, Ramos de Azevedo, Santa Ifigênia, São Bento, Correios, $\mathrm{Pi}$ ques e Memória. Cada uma delas conta com
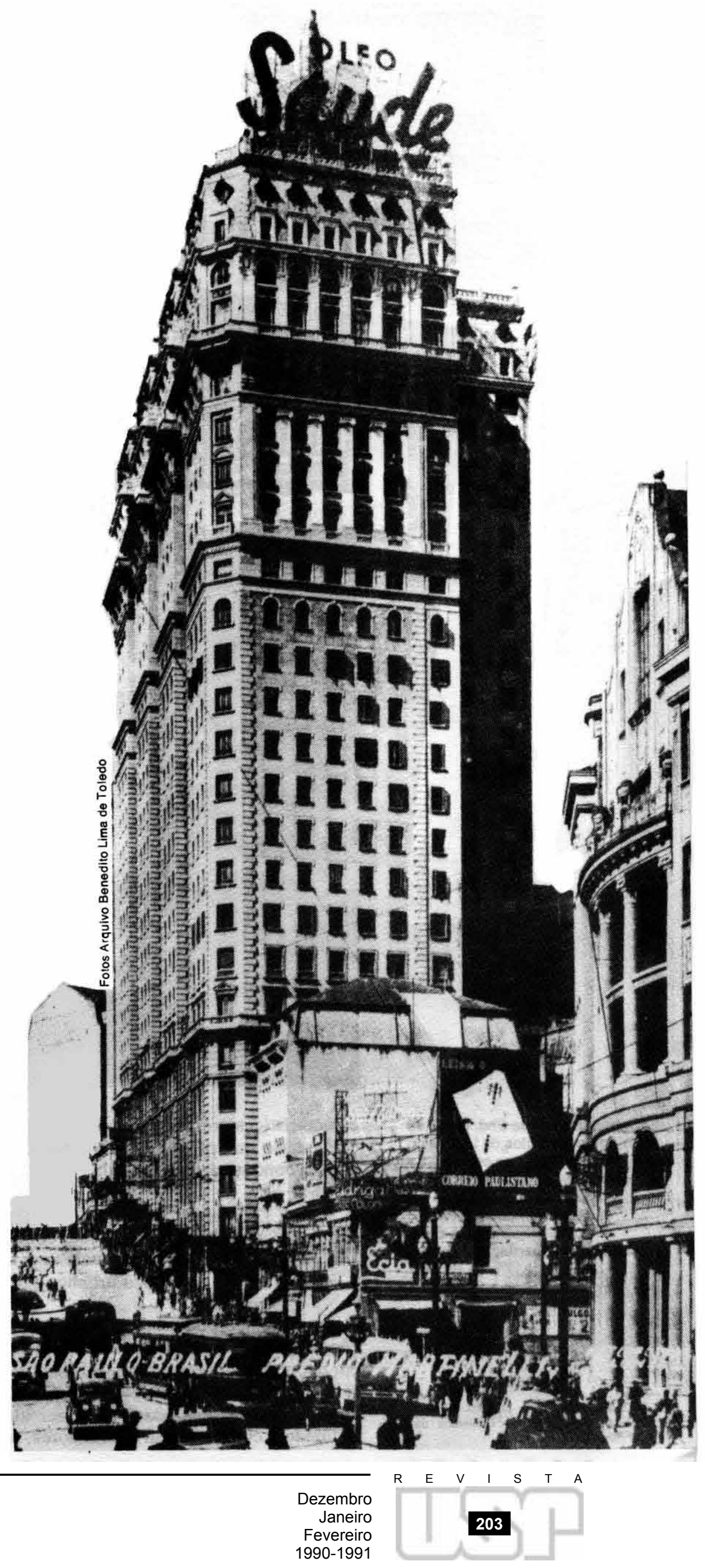

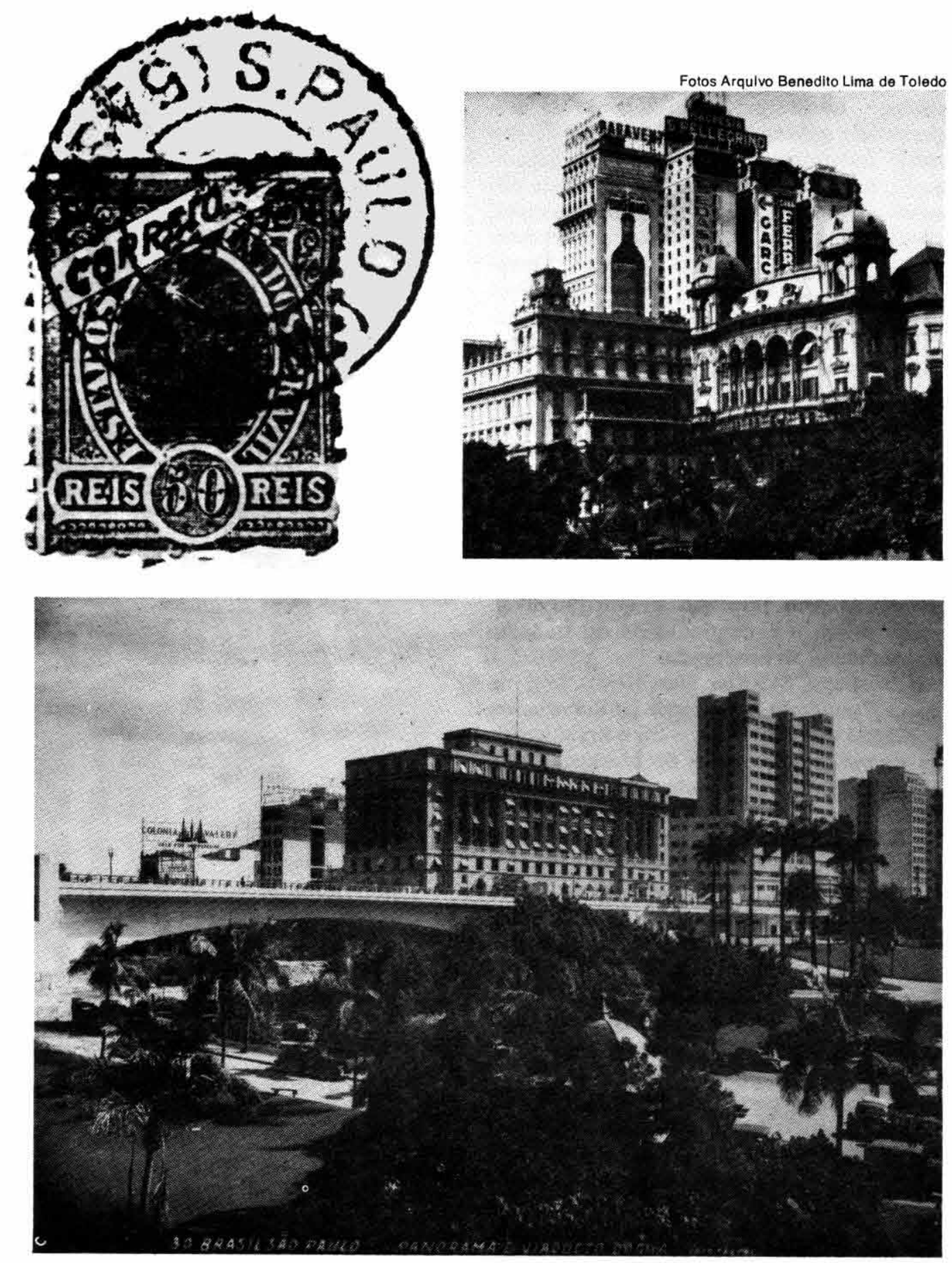

O novo viaduto do Chá, tendo ao fundo os edifíclos da Light e do Mappin. O parque começava a ser invadido pelos automóvels.

Acima à direita, detalhe de um cartão-postal em que se vé o edificio Martineill, já multo popular; à esquerda, selo do ano de 1901

60 acervo de seus projetos também está conservado na Blblioteca da FAU-USP.

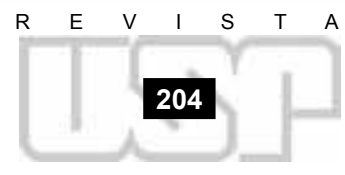

características próprias, mas é impossível dissociá-las da história e do espaço do vale. $\mathrm{O}$ comentário que propõe para o largo da Memória, projeto de Victor Dubugras ${ }^{(6)}$, resume a idéia condutora do trabalho:

"Finalmente o largo da Memória, logradouro que conserva o monumento mais antigo da cidade, como vimos, recebeu um projeto de superiores qualidades, dentre as quais uma merece destaque, por ser um atributo das grandes obras no espaço urbano: a de parecer sempre haver existido".

Por fim, não pode deixar de ser valorizado o papel da FIESP ao tornar viável a edição, a qual, pelo seu vulto, não teria guarida no mercado editorial corrente. No entanto, em decorrência mesmo desta origem, a obra tornou-se de difićlima obtenção, acessível somente a alguns iniciados. A sua distribuição a algumas bibliotecas especializadas não elimina esta lacuna, passível de ser ultrapassada com nova edição, talvez em formato reduzido e custos industriais menores, colocada no mercado livreiro. 